\title{
A complete view of the atmospheric hydrologic cycle
}

\author{
Dipanjan Dey $^{1,2}$, Aitor Aldama Campino ${ }^{1}$, and Kristofer Döös ${ }^{1}$ \\ ${ }^{1}$ Department of Meteorology, Stockholm University, 10691 Stockholm, Sweden \\ ${ }^{2}$ College of Engineering, Mathematics and Physical Sciences, University of Exeter, Exeter, UK
}

Correspondence: Dipanjan Dey (dipanjanrocks01@ gmail.com)

\begin{abstract}
The global atmospheric water transport from the evaporation to the precipitation regions has been traced using Lagrangian trajectories. A matrix has been constructed by selecting various group of trajectories based on their surface starting (evaporation) and ending (precipitation) positions to show the connectivity of the atmospheric water transport within and between the three major ocean basins and the global landmass. The analysis reveals that a major portion of the evaporated water precipitates back into the same region, namely $67 \%$ for the Indian, $64 \%$ for the Atlantic, $85 \%$ for the Pacific Ocean and $72 \%$ for the global landmass. The evaporation from the subtropical regions of the Indian, Atlantic and Pacific Oceans is found to be the primary source of atmospheric water for precipitation over the Intertropical Convergence Zone (ITCZ) in the corresponding basins. The evaporated waters from the subtropical and western Indian Ocean were traced as the source for precipitation over the South Asian and Eastern African landmass, while Atlantic Ocean waters are responsible for rainfall over
\end{abstract} North Asia and Western Africa. Atlantic storm tracks were identified as the carrier of atmospheric water that precipitates over Europe, while the Pacific storm tracks were responsible for North American, eastern Asian and Australian precipitation. The bulk of South and Central American precipitation is found to have its source in the tropical Atlantic Ocean. The recycling of evapotranspirated water from land is pronounced over the western coast of South America, Northeastern Asia, Canada and Greenland. The ocean-to-land and land-to-ocean water transport through the atmosphere was computed to be $2 \times 10^{9} \mathrm{~kg} / \mathrm{s}$ and

$1 \times 10^{9} \mathrm{~kg} / \mathrm{s}$, respectively. The difference between them (net ocean-to-land transport), i.e. $1 \times 10^{9} \mathrm{~kg} / \mathrm{s}$, is transported to land. This net transport is approximately the same as found in previous Eulerian estimates.

\section{Introduction}

The hydrologic cycle traces the continuous movement of the water in the coupled ocean-atmosphere system. The atmospheric hydrological cycle starts from the evaporation regions and ends in the precipitation regions. Generally evaporation tends to exceed precipitation over the ocean, while for land the opposite holds true. A consequence of this excess precipitation over land is that this surplus water eventually discharges into the ocean by the rivers, completing the atmospheric branch of the water cycle. The hydrological cycle is believed to strengthen in a future warmer climate. The Clausius-Clapeyron (CC) thermodynamic relation indicates that for every $1^{\circ} \mathrm{C}$ temperature rise, the saturation vapour pressure will approximately increase by $7 \%$. This implies that the vapour pressure, which is equivalent to the specific humidity or the amount of moisture in the atmosphere (Wallace and Hobbs, 2006), will also increase, as the tropospheric relative humidity is believed to remain the same in a warmer climate (Soden and Held, 2006). If the atmospheric circulation would remain unchanged, the water-vapour increase will solely 
act to intensify the moisture transport from the evaporation regions to the precipitation areas and help to magnify the strength of the existing global evaporation $(\mathrm{E})$ - precipitation $(\mathrm{P})$ patterns. This is the paradigm of "dry gets drier and wet gets wetter" or in other words "rich-get-richer mechanism" (Chou and Neelin, 2004). However, the increase of atmospheric moisture in a warmer climate does not necessarily imply that the global evaporation and precipitation will also increase by the same CC rate, as these are constrained by the surface energy budget (Held and Soden, 2006; Huntington, 2006). Analyses of future climate scenarios from Earth system models have revealed a 2-3\% increase in global precipitation per $1^{\circ} \mathrm{C}$ temperature rise (Allan et al., 2014). The imbalance between increasing rate of moisture and precipitation ensures that the precipitation intensity will increase in the future climate, while the frequency and duration are apt to decrease (Trenberth, 1999). In addition to this, the hydrologic cycle also plays a critical role in the global energy cycle through evaporative cooling of the Earth's surface and latent heating of the atmosphere. The impact of the hydrologic cycle is not only important for the atmosphere but also for the ocean. The evaporation-dominated regions over the ocean generally leads to high salinity and the precipitation-dominated regions to low salinity. The Atlantic Ocean is e.g. a net freshwater flux surplus ( $\mathrm{E}-\mathrm{P}>0)$ region in contrast to the Pacific Ocean, where the opposite holds true. This in turn gives rise to a salinity asymmetry, which can explain the generation of deep water in the North Atlantic but not in the North Pacific Ocean (Warren, 1983; Broecker et al., 1985; Emile-Geay et al., 2003). The North Atlantic Deep Water (NADW) is an integral part of the Atlantic Meridional Overturning Circulation (AMOC), which distributes heat within the climate system (Vellinga and Wood, 2008). It is projected by many climate models that the AMOC will weaken during the 21st century, which could be linked to changes in the hydrologic cyle (Stocker et al., 2014).

Given these diverse roles of the hydrologic cycle within the Earth system, it is important to disentangle and understand its different parts. Previous studies were able to provide an estimate of the water storage in the reservoirs and also the exchange of water between them (Chahine, 1992; Trenberth et al., 2007, 2011). The atmospheric water transport between the global ocean and land, the two dominating water reservoirs, are primarily obtained by integrating the net freshwater flux (E - P) over

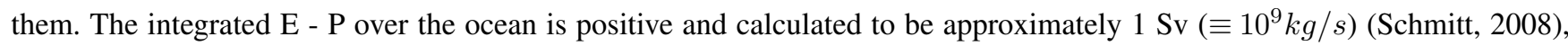
which is transported to land. Due to water-mass conservation this $1 \mathrm{~Sv}$ is equivalent to the negative $\mathrm{E}-\mathrm{P}$ integral over land (as P > E over the land) and will return to the ocean through river discharges. The E - P can either be directly obtained from the observationally based reanalysis data sets or derived from the moisture budget analysis (Trenberth et al., 2011). These kinds of studies suffer from the limitation that they can not provide information about the atmospheric water transport within and between different ocean basins and land. In addition, knowledge about how much of the ocean/land evaporated water truly precipitates over the ocean/land itself and is transported to the land/ocean is not achievable. In the present study, these questions will be possible to address using a new Lagrangian framework. The primary objective of the present study is to link atmospheric water transports within and between different ocean basins and land using Lagrangian trajectories, which makes it possible to trace water from the evaporation at the surface to where it precipitates. This will facilitate the construction of an atmospheric freshwater connectivity matrix, which will provide both quantitative as well as qualitative descriptions of the atmospheric water exchange. 


\section{Methods and data}

\subsection{Lagrangian model for tracing water in the atmosphere}

The mass conserving Lagrangian trajectory model TRACMASS v7.0 (Aldama-Campino et al., 2020; Döös, 1995) was used in the present study to obtain a detailed understanding of the global hydrologic cycle. One of the unique characteristics of TRACMASS is that it uses mass transports through the model grid box faces instead of velocity fields (Vries and Döös, 2001). TRACMASS was employed frequently to track the oceanic water-transport pathways (Berglund et al., 2017, 2021; Döös et al., 2008) and atmospheric air-mass routes (Kjellsson and Döös, 2012). In Dey and Döös (2020) TRACMASS was updated in order to trace water instead of air in the atmosphere. The atmospheric water tracing version of TRACMASS was also implemented recently to study the seasonal and inter-annual characteristics of the South Asian summer monsoon precipitation (Dey and Döös, 2021). Note here that this trajectory calculations are based on atmospheric water-mass transport in $\mathrm{kg} / \mathrm{s}$ and not transports of humid air. We are hence tracing the actual atmospheric water and not the moisture change along air-parcel trajectories. An elaborate evaluation of the atmospheric and oceanic trajectory schemes that are used in TRACMASS can be found in Döös et al. (2017).

The horizontal water transports through the model grid box faces are obtained by multiplying the air transports with its water content. The vertical water transport field is then obtained from an atmospheric water-mass conservation equation (Dey and Döös, 2019), which is integrated from the top of the atmosphere down to the surface of the earth. Thus, the vertical water transport includes evaporation and precipitation in addition to the advection of moisture by the winds. At the surface the integrated vertical water transport should hence be equal to E - P, which was illustrated by Dey and Döös (2020). Note that the diffusive water transports were omitted in Dey and Döös $(2019,2020)$, as well as in the present study due to its unavailability from the ERA-Interim but could be included in future studies. For a detailed mathematical derivation of the atmospheric water transport see Dey and Döös (2019, 2020, 2021).

The mass conserving ability of TRACMASS (i.e. mass transport of a trajectory is conserved throughout its journey) has made it possible to compute Lagrangian stream functions from the simulated trajectories. The Lagrangian stream function is an useful tool to understand atmospheric and oceanic circulation pathways and has been used in previous studies extensively (Blanke et al., 1999; Berglund et al., 2017; Kjellsson and Döös, 2012; Döös et al., 2008). In the present study the Lagrangian meridional and zonal overturning stream functions were computed to quantify atmospheric water-mass transport pathways in the meridional-vertical and zonal-vertical coordinate system respectively. The Lagrangian meridional overturning stream function can be expressed as

$\psi_{j, k}=\sum_{k^{\prime}=k}^{k z} \sum_{i} \sum_{m} T_{i, j, k^{\prime}, m}^{y} \quad$,

here, $i, j, k^{\prime}$ are the zonal, meridional and vertical coordinates through which the trajectory indexed $m$ passes. $T_{i, j, k^{\prime}, m}^{y}$ is the atmospheric water transport $\left(\mathrm{kg} \mathrm{s}^{-1}\right)$ by the trajectory indexed $m$ through the zonal-vertical grid box. The highest vertical level of the atmosphere is at $0.1 \mathrm{hPa}$ and denoted as $k^{\prime}=k z$. Note that the streamlines will be open and crossing the surface due to 
the sources (evaporation) and sinks (precipitation) of atmospheric water. Similarly, the Lagrangian zonal overturning stream function was computed as:

$\psi_{i, k}=\sum_{k^{\prime}=k}^{k z} \sum_{j} \sum_{m} T_{i, j, k^{\prime}, m}^{x} \quad$,

where $T_{i, j, k^{\prime}, m}^{x}$ is the Lagrangian water transport $\left(\mathrm{kg} \mathrm{s}^{-1}\right)$ through the meridional-vertical grid-box face. The vertically integrated zonal $\left(F_{i, j}^{x}\right)$ and meridional $\left(F_{i, j}^{y}\right)$ water flux was computed from the simulated water trajectories to describe atmospheric water transport pathways in longitude-latitude framework:

$F_{i, j}^{x}=\frac{\sum_{k^{\prime}=0}^{k z} \sum_{m} T_{i, j, k^{\prime}, m}^{x}}{\Delta y_{i, j}}$,

$F_{i, j}^{y}=\frac{\sum_{k^{\prime}=0}^{k z} \sum_{m} T_{i, j, k^{\prime}, m}^{y}}{\Delta x_{i, j}}$

100 The longitudinal and latitudinal grid spacing is denoted as $\Delta x$ and $\Delta y$ respectively. The resultant of the vertically integrated horizontal water flux is thus

$F_{i, j}=\sqrt{\left(F_{i, j}^{x}\right)^{2}+\left(F_{i, j}^{y}\right)^{2}}$,

which has the unit $S v / m\left(1 S v \equiv 10^{9} \mathrm{~kg} \mathrm{~s}^{-1}\right)$. The calculated water trajectories were also used to compute atmospheric water residence time $\left(\tau_{i, j}\right)$ following Dey and Döös $(2020,2021)$

$\tau_{i, j}=\frac{\sum_{m=1}^{M}\left\{\left(t_{m}^{P}-t_{m}^{E}\right) \cdot T_{i, j, m}^{z}\right\}}{\sum_{m=1}^{M} T_{i, j, m}^{z}}$,

which shows lifetime of the atmospheric water between evaporation and precipitation. Here $T_{i, j, m}^{z}$ is the water transport of the trajectory indexed $m$ through the surface. $M$ is the total number of trajectories, $t^{P}$ and $t^{E}$ is the time when the atmospheric water trajectories precipitate and evaporate respectively.

\subsection{Data source}

The atmospheric water transports were computed using the surface pressure, specific humidity, specific cloud liquid and ice water content and horizontal wind velocities from the ERA-Interim reanalysis (Dee et al., 2011). The data sets were obtained for the years 2016 and 2017 with $0.75^{\circ}$ spatial resolution, 6-hourly temporal resolution and 60 hybrid vertical model levels. It is noteworthy that to satisfy the mass conservation property of the Lagrangian model TRACMASS it requires data at model levels and not at interpolated pressure levels (Dey and Döös, 2021).

\subsection{Lagrangian study configuration}

To understand the global atmospheric water transport the Lagrangian trajectories were started over the entire surface of the globe when evaporation exceeded precipitation and followed until they reach back to the surface, which occurs when precipitation exceeded evaporation. These water trajectories were started at the surface every 6 hours during 2016 where E $>$ P and 


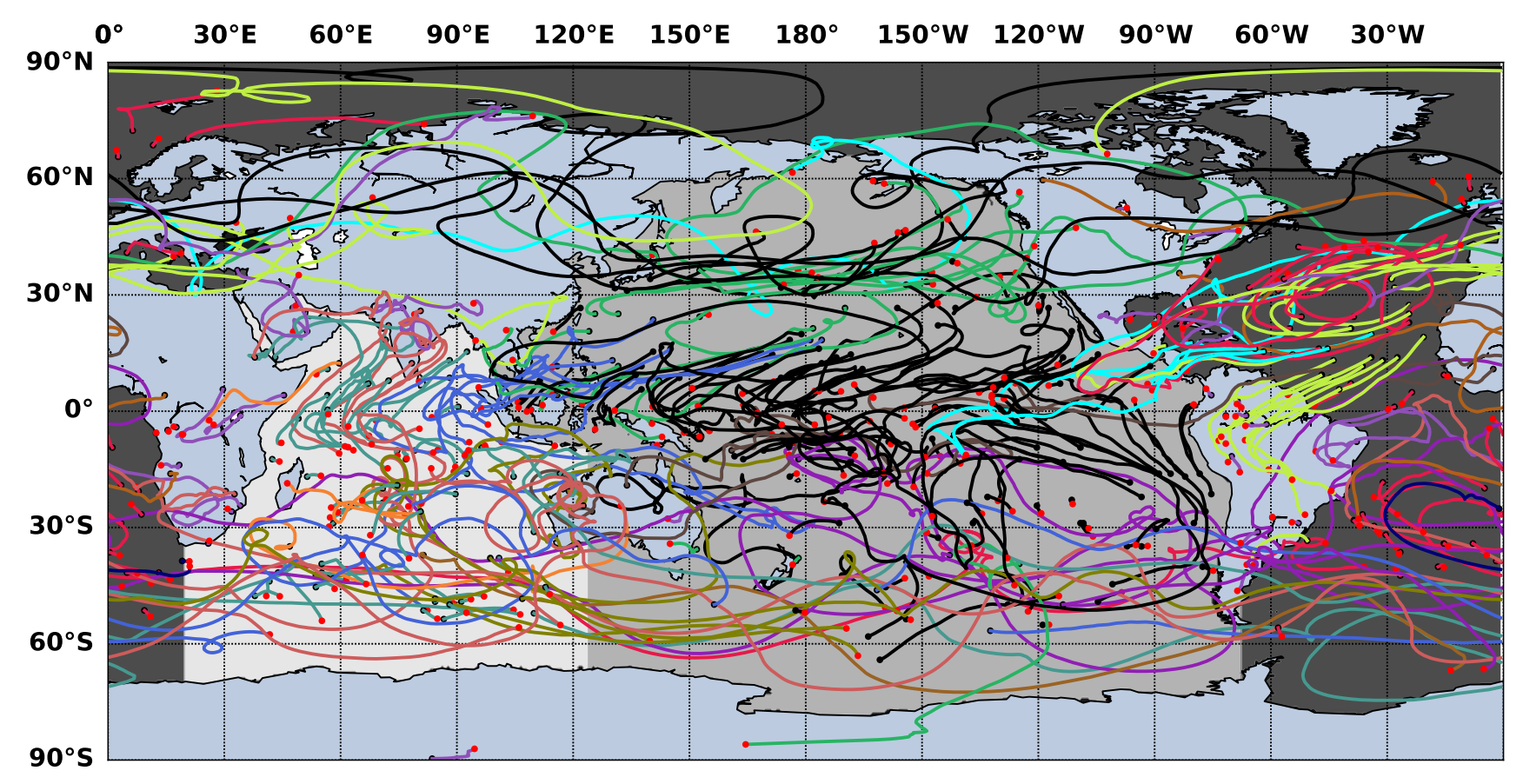

Figure 1. Spaghetti plot of few selected atmospheric water trajectories for the month of January 2016. The selected ocean basins are represented by different shadings of gray and defined as the Indian Ocean (IO), Pacific Ocean (PO) and Atlantic Ocean (AO). Note that, the Arctic Ocean is included in the Atlantic. The global landmass is taken as one single entity. The atmospheric water transport within and between the ocean basins and land has been calculated based on these defined sectors. The representative trajectories associated with these intra- and inter-basin water transport are labeled with different colors. The black dots are indicating the starting points and red points represent the ending points of the atmospheric water trajectories.

followed until they reached back the surface where $\mathrm{P}>\mathrm{E}$. The trajectories were, however, followed for a maximum of one year. Only $0.4 \%$ remained in the atmosphere after one year and were subsequently discarded. The atmospheric water transport connection within and between different ocean basins and land, which can be regarded as an atmospheric water connectivity matrix, was estimated by sorting different classes of atmospheric trajectories based on their starting and ending positions. In the present study, the starting and ending points of the water trajectories were classified into the global landmass and the three major ocean basins as defined in Figure 1. The ocean basins are termed the Indian, Pacific, and the Atlantic Ocean (including the Arctic ocean). 

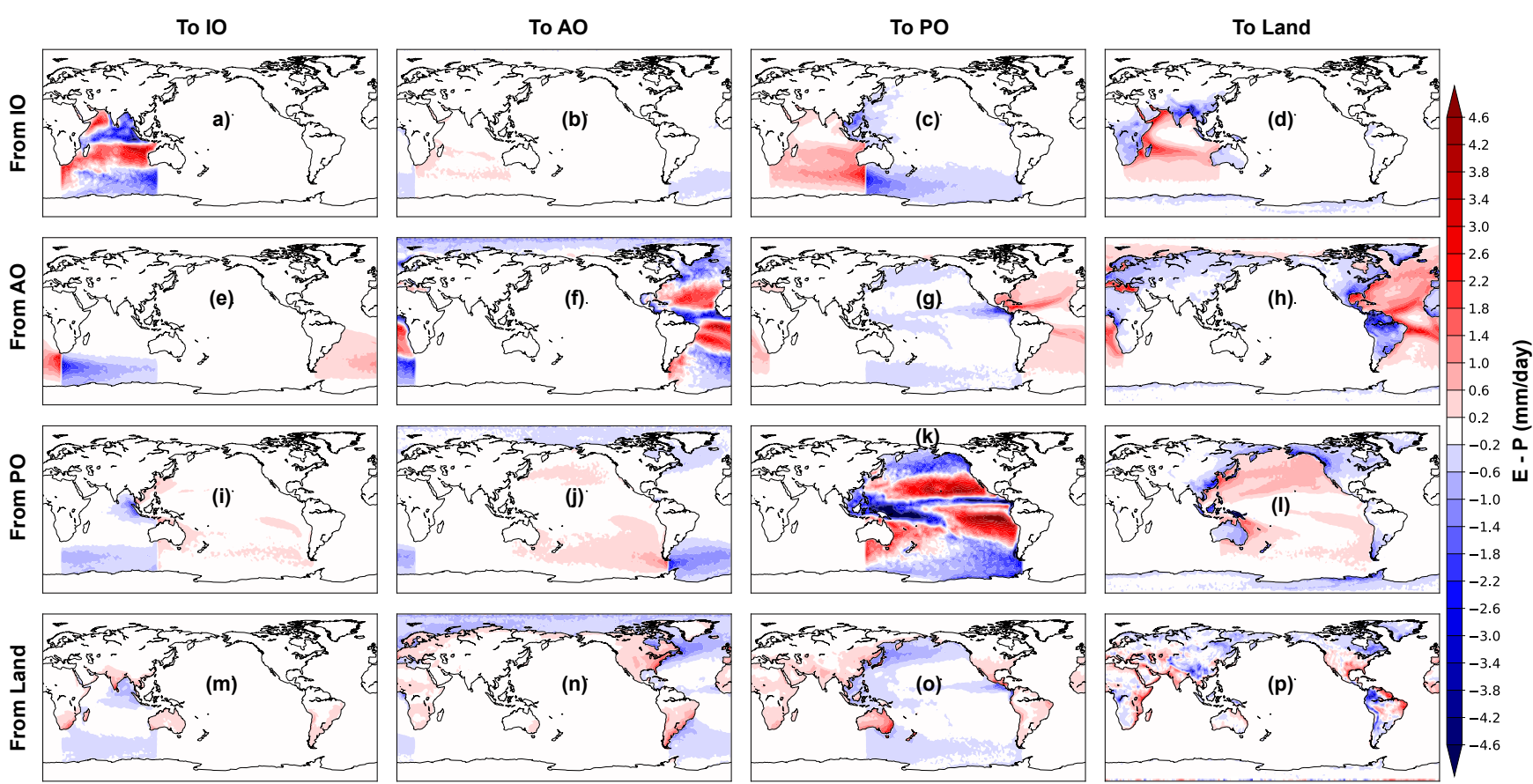

Figure 2. Annual mean E - P (mm/day) inferred from the atmospheric waters travelling from the surface evaporative regions (red contours) to the precipitation areas (blue contours). The rows represent the evaporative (starting points of the atmospheric water trajectories) sectors and the columns represent the precipitation (ending points of the trajectories) regions.

\section{Results}

\subsection{Atmospheric water connectivity}

The atmospheric water is always on the move through space and in time within the climate system. In order to grasp the full characteristics of the atmospheric water circulation, it is thus necessary to reduce its dimensionality. The geographical connection of the atmospheric water transports within and between the ocean basins and the global landmass has been established by tracing the atmospheric water from the evaporation to the precipitation regions (Fig. 2), which are the starting and ending points of the trajectories. Additionally, a quantitative view of this geographical atmospheric water transport connection is presented in Table 1 by integrating the evaporation/precipitation transport obtained from the sorted classes of trajectories. This integration of either evaporation or precipitation will give the same result due to the mass-conserving property of the Lagrangian model TRACMASS. The atmospheric water movement in the horizontal-vertical plane is obtained by calculating the Lagrangian overturning water-mass stream functions using equation 1 and 2 and presented in latitude-pressure and longitude-pressure coordinate systems (Fig. 3 and Fig. 4 respectively). In addition, vertically integrated horizontal water flux computation (using equation 5) is used to describe the water transport routes in longitude-latitude framework (Fig. 5). Note that the streamlines represent the integrated atmospheric water transport routes and is based on the sum of the Lagrangian 


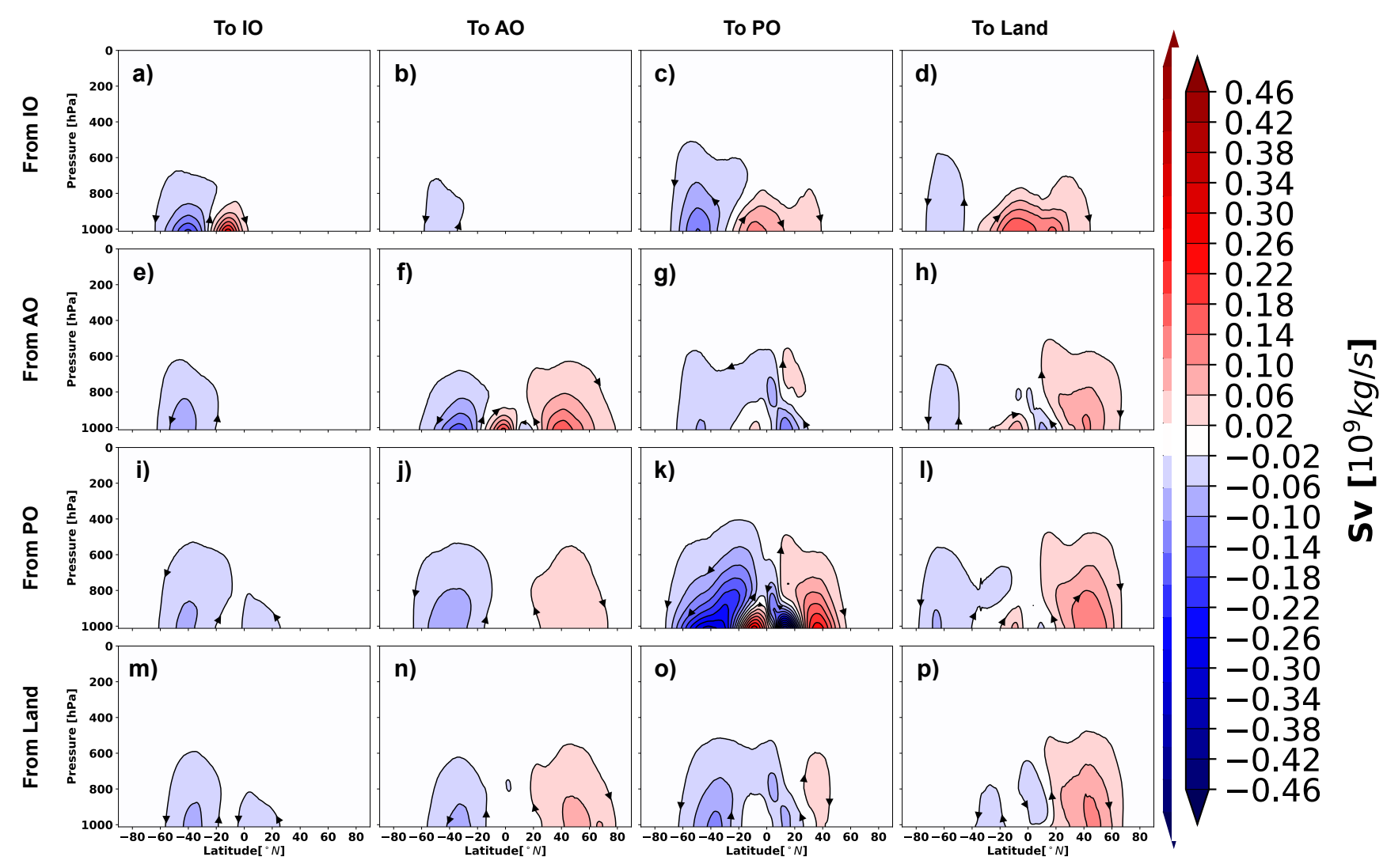

Figure 3. The Lagrangian meridional overturning stream function within and between the ocean basins and land. This has been undertaken by grouping the trajectories according to their starting and ending locations. The starting and ending points of the atmospheric trajectories are defined as per the sectors presented in Fig. 1.

trajectories, which should not be confused with the paths of the individual trajectories. Additionally, the streamlines start at the surface when $\mathrm{E}>\mathrm{P}$ and terminate where the opposite holds true. While interpreting the atmospheric water pathways from the meridional and zonal overturning stream functions, it should be remembered that these are zonally and meridionally integrated pathways respectively. For instance, the atmospheric water mass crossing a longitude can be transported zonally both by the tropical easterly trade winds and by the mid-latitude westerlies. If e.g. the westerlies transport more water than the easterlies at the same longitude then the meridionally integrated zonal overturning stream function will only show the dominant westerly signal. The residence time of the atmospheric water was mapped geographically at the evaporation points using equation (6). This mapping was split up using the connectivity matrix so that the residence times indicate the inter- and intra-basin transport time scales (Fig. 6). This residence time was calculated from the points where net evaporation exceeds a monthly mean value of $0.2 \mathrm{~mm} /$ day in order to focus on the main source regions of the atmospheric water.

The results show that the evaporation from the subtropical Atlantic, Pacific and Indian Ocean is the major source of water for precipitation over the Intertropical Convergence Zone (ITCZ) in their respective basins (Fig. 2a, 2f and 2k). A major portion of 
Table 1. Atmospheric freshwater transport within and between the ocean basins and land. The rows represent evaporative (atmospheric water source) sectors and the columns the precipitation (atmospheric water sink) regions. Units are in $\mathrm{Sv}\left(\equiv 10^{9} \mathrm{~kg} / \mathrm{s}\right)$. The percentages in the parentheses represent fractions of the net evaporation that are transported from the source region.

\begin{tabular}{|c|c|c|c|c|}
\hline Regions & Indian Ocean & Atlantic Ocean & Pacific Ocean & Land \\
\hline Indian Ocean & $2.26(67 \%)$ & $0.10(3 \%)$ & $0.52(15 \%)$ & $0.52(15 \%)$ \\
\hline Pacific Ocean & $0.23(3 \%)$ & $0.34(4 \%)$ & $7.52(85 \%)$ & $0.77(8 \%)$ \\
\hline Land & $0.20(5 \%)$ & $0.48(10 \%)$ & $0.61(13 \%)$ & $3.30(72 \%)$ \\
\hline
\end{tabular}

the evaporated water from the ocean basins was found to precipitate over their source sectors (Table 1). On an annual average, $67 \%(2.26 \mathrm{~Sv}), 64 \%(3.07 \mathrm{~Sv})$ and $85 \%(7.52 \mathrm{~Sv})$ of the evaporation from the Indian, Atlantic and Pacific Ocean precipitates over the same oceanic basin (Table 1). The meridional overturning stream function and vertically integrated horizontal water transport corresponding to these intra-basin atmospheric water transports (Fig. (3a; 5a), Fig. (3f; 5f) and Fig. (3k; 5k)) show that the Equatorward meridional transport in the Atlantic and the Pacific Oceans and northward transport in the Indian Ocean are dynamically responsible for most of the oceanic ITCZ rainfall. The easterly (east-to-west) water transport within the Pacific Ocean (blue cell in Fig. 4k and black lines in Fig. 5k) also plays a crucial role for the Pacific ITCZ precipitation and shows the atmospheric water movement within the Walker circulation. The evaporative waters from the Indian, Atlantic and Pacific Oceans stay on an average 4, 3 and 5 days, respectively, in the atmosphere before precipitating back into their basins of origin (Fig. 6a, 6f and 6k). Note that the residence-time map has a large spectrum of values and varies a lot within small distances in some of the defined regions, e.g. the evaporative water from the subtropical Pacific Ocean has residence time from 0 days to more than 24 days (Fig. 6k). The rainfall over the South Asian landmass and Eastern Africa is traced to originating and transporting mostly from the subtropical and Western Indian Ocean (Fig. 2d and Fig. 5d). Note that this is an annual-mean figure and consists of precipitation signals from the entire year. The atmospheric water transport from the Indian Ocean to the landmass is estimated to be around $0.52 \mathrm{~Sv}$, which is $15 \%$ of the total Indian Ocean evaporation (Table 1). The evaporated water from the Indian Ocean is primarily transported by the Somali low-level jet to the South Asian landmass. This low-level jet is a southwesterly flow which is active along the Somali coast during the summer monsoon months of June to September. The atmospheric water transport pathways associated with this jet is captured by the meridional and zonal overturning stream functions (Fig. 3d and Fig. 4d), in which the Northward (Fig. 3d) and Eastward (Fig. 4d) flow components carry atmospheric water to South Asia. Additionally, the horizontal water transport pathway from the Indian Ocean to the South Asian landmass by the Somali low-level jet is clearly noticeable in Fig. $5 \mathrm{~d}$.

The Easterly (Fig. 4d and Fig. 5d) component of the flow field transport water to Eastern Africa from the nearby Indian Ocean. The water that evaporated from the Indian Ocean and transported to land remains around 20 days in the atmosphere

(Fig. 6d). The transport from the subtropical Atlantic Ocean to the tropical and mid-latitude Pacific Ocean (Fig. 2g) is found to be accomplished by the Easterly and Westerly winds, respectively, (Fig. $4 \mathrm{~g}$ and Fig. 5g) and is calculated to be approximately 

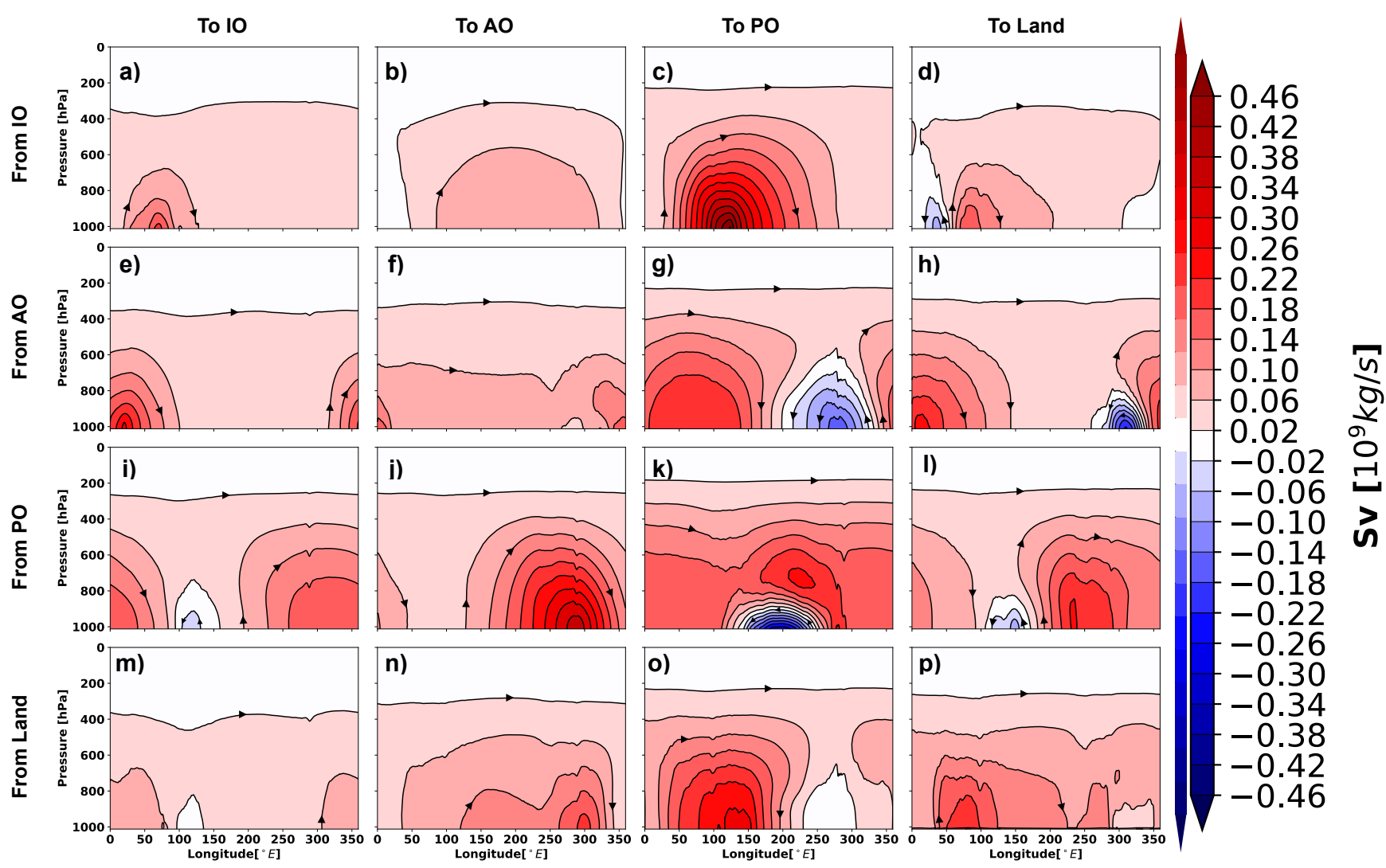

Figure 4. Same as Fig. 3 but for the zonal overturning stream function.

$0.45 \mathrm{~Sv}$ (Table 1). The mean residence time of the evaporated waters from the Atlantic Ocean that are transported to the Pacific Ocean is 35 days (Fig. 6g). The majority of the South and Central American precipitation is found to be transported from the tropical Atlantic (Fig. 2h) with the help of Easterly trade winds (blue cell in Fig. 4h and black lines in Fig. 5h). The Atlantic storm tracks, which orientated in an eastward direction, seemed to be responsible for the European and North Asian precipitation (Fig. 2h, $4 \mathrm{~h}$ and $5 \mathrm{~h}$ ). The annual-mean Western African precipitation that is dominated by the Western African monsoon is traced to originating from the Atlantic Ocean and moves eastward (Fig. 2h and 4h). The winds over the Atlantic Ocean transport around 1.07 Sv atmospheric water to the land, which is $22 \%$ of its total evaporation (Table 1). The Atlantic Ocean evaporated waters are stay in the atmosphere for 15 days before precipitating over Land (Fig. 6h). The rainfall over the west coast of North America, eastern coasts of Asia and Australia is primarily sourced from the Pacific Ocean (Fig. 21) and its pattern closely resembles the pathways of the Pacific storm tracks. The total atmospheric water transport from the Pacific Ocean to the landmass is approximately $0.77 \mathrm{~Sv}$ (Table 1). The average residence time of the waters that are evaporated from the Pacific Ocean and precipitated over the landmass is found to be 21 days (Fig. 61). The global landmass evaporated water mostly precipitates over the western coast of South America, the Northeastern sector of Asia, Canada and Greenland (Fig. 2p). 

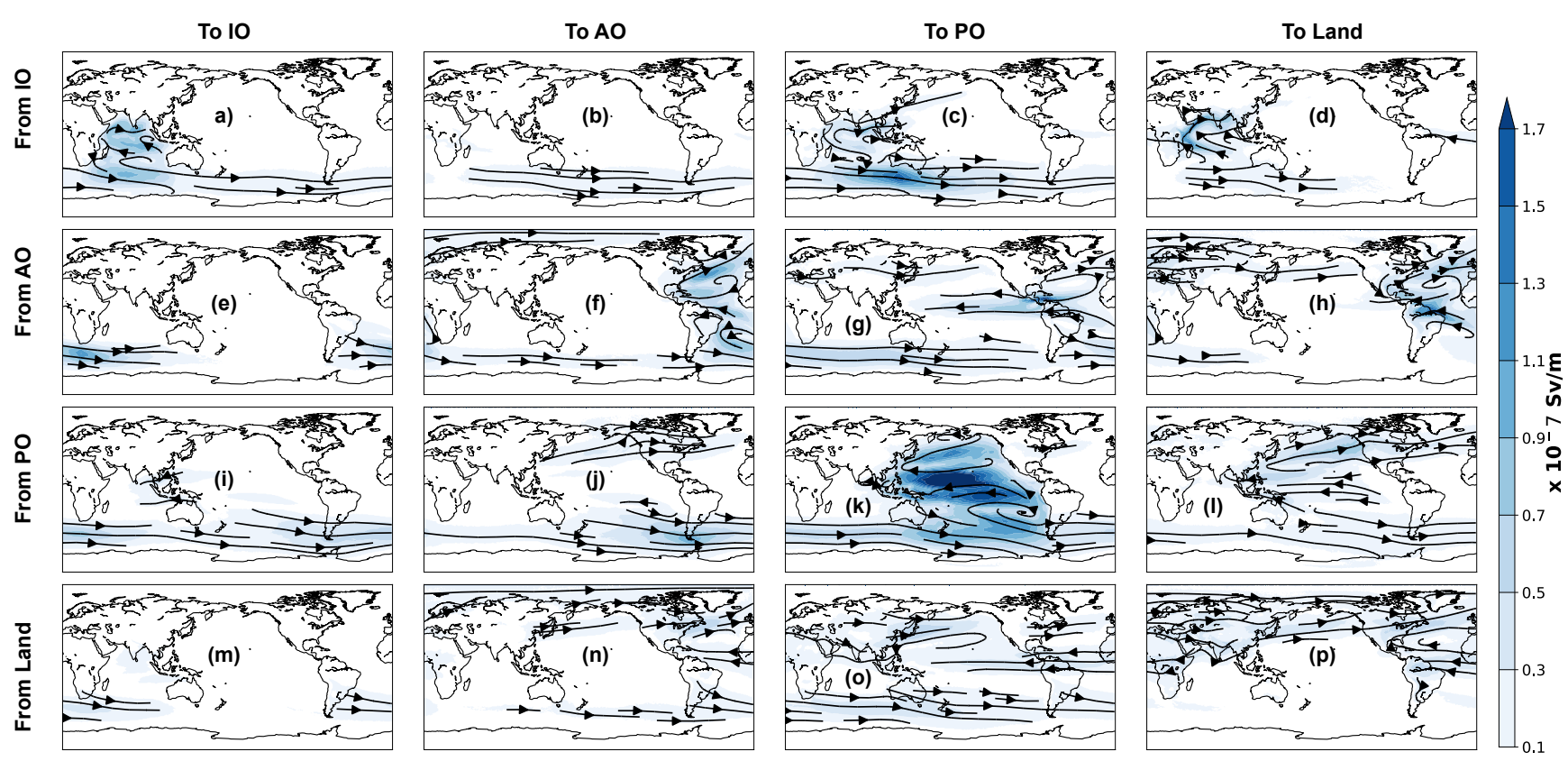

Figure 5. The vertically integrated horizontal water flux (shaded; $S v \mathrm{~m}^{-1}$ ) within and between the ocean basins and land. This has been achieved by grouping the atmospheric water trajectories according to their starting and ending locations. The starting and ending points of the Lagrangian trajectories are defined as per the sectors presented in Fig. 1. The flux directions are given by the black lines.

The total amount of recycled atmospheric water transport over land is estimated to be around $3.30 \mathrm{~Sv}$ and is equal to $72 \%$ of its evapotranspiration (Table 1). The evapotranspirated water from land that falls back over the continents spends 6 days in the atmosphere (Fig. 6p).

\subsection{A simplified quantitative view of the atmospheric water cycle}

A simplified schematic of the annual mean global atmospheric water transports from both the Eulerian and Lagrangian perspectives is presented in Fig. 7. It reflects the advantage of using a Lagrangian framework, from which ocean-to-ocean, oceanto-land, land-to-land and land-to-ocean atmospheric water transport could be and was calculated (Fig. 7, bottom). The sketch was constructed by summing and rounding off the values of Table 1. For instance, net evaporation over the entire ocean was calculated by summing all the values of the atmospheric water transports from the defined ocean basins. The net evaporative transport from all the ocean basins is around $17 \mathrm{~Sv}$, of which nearly $16 \mathrm{~Sv}$ precipitates over the ocean itself. The net oceanto-land transport is thus $1 \mathrm{~Sv}$, which returns to the ocean as runoff from land and equals the difference between the land net evaporation $(\approx 4.6 \mathrm{~Sv})$ and land net precipitation $(\approx 5.6 \mathrm{~Sv})$. It is found that $88 \%$ of the oceanic net evaporation (i.e. approximately $15 \mathrm{~Sv}$ ) transported back to the ocean through precipitation. The ocean-to-land transport is computed to be around 2 $\mathrm{Sv}$, while the land-to-ocean atmospheric water transport is approximately $1 \mathrm{~Sv}$. The difference between them (i.e. $1 \mathrm{~Sv}$ ) is the same as the net ocean-to-land water transport through the atmosphere one might obtain from an Eulerian point of view. The net 

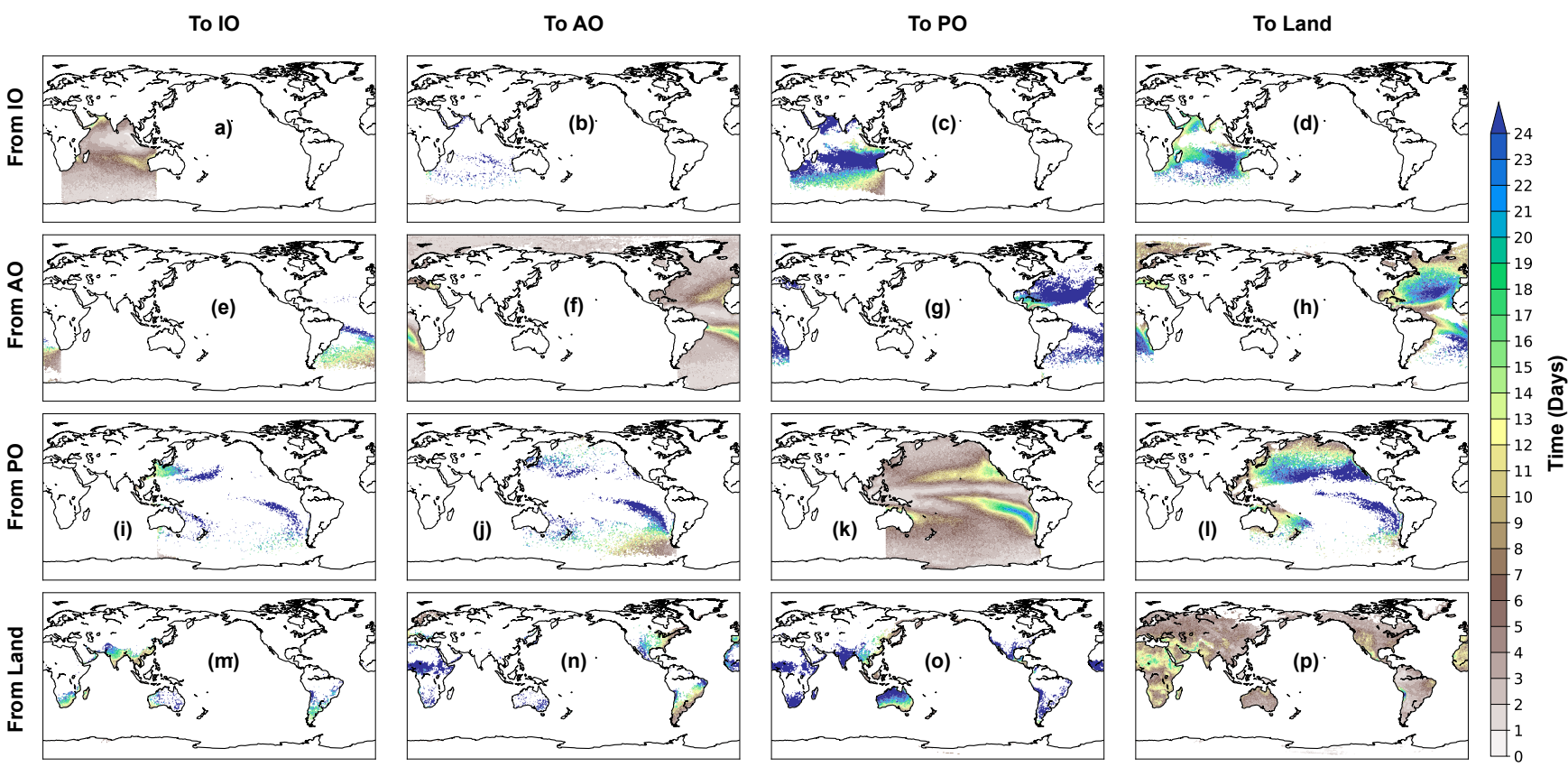

Figure 6. The average residence time (days) of the atmospheric waters travelling from the surface evaporative regions (red contours) to the precipitation areas (blue contours) in Fig. 2. This residence time was calculated from the points where net evaporation exceeds a monthly mean value of $0.2 \mathrm{~mm} /$ day.

land evapotranspiration is calculated to be around $4.6 \mathrm{~Sv}$ and $72 \%$ of this (i.e. around $3.3 \mathrm{~Sv}$ ) goes into terrestrial precipitation. Note that this net evaporative and precipitating transports should underestimate the earlier Eulerian estimates (Trenberth et al., 2007). This since in the present study, atmospheric water is traced from the net evaporation ( $\mathrm{E}-\mathrm{P}>0)$ to the net precipitation points $(\mathrm{E}-\mathrm{P}<0)$ and not from the total evaporation $(\mathrm{E})$ to the total precipitation $(\mathrm{P})$. The computation of the vertical mass transport of atmospheric water in the present study omits diffusive atmospheric water transport, specific rain and snow water content and thus leading towards an overestimate of the net evaporative and precipitating transports as compared to the total evaporation and precipitation estimates from previous studies, e.g. Trenberth et al. (2007). At any given time, the instantaneous net evaporation $(\mathrm{E}-\mathrm{P}>0)$ and total evaporation might roughly be the same, if assuming that evaporation and precipitation cannot coexist at the same time but the present study uses 6-hourly cumulative net freshwater transport.

\section{Discussion}

215 One of the most striking and robust features of climate change is the acceleration of the atmospheric water cycle branch, which is associated with the temperature increase of the lower troposphere. In order to gain a detailed understanding of the future atmospheric water cycle and its importance, one should know the intricacies of the present-climate water cycle in the atmosphere. Although earlier studies were able to provide a quantification of the global atmospheric water cycle but they 


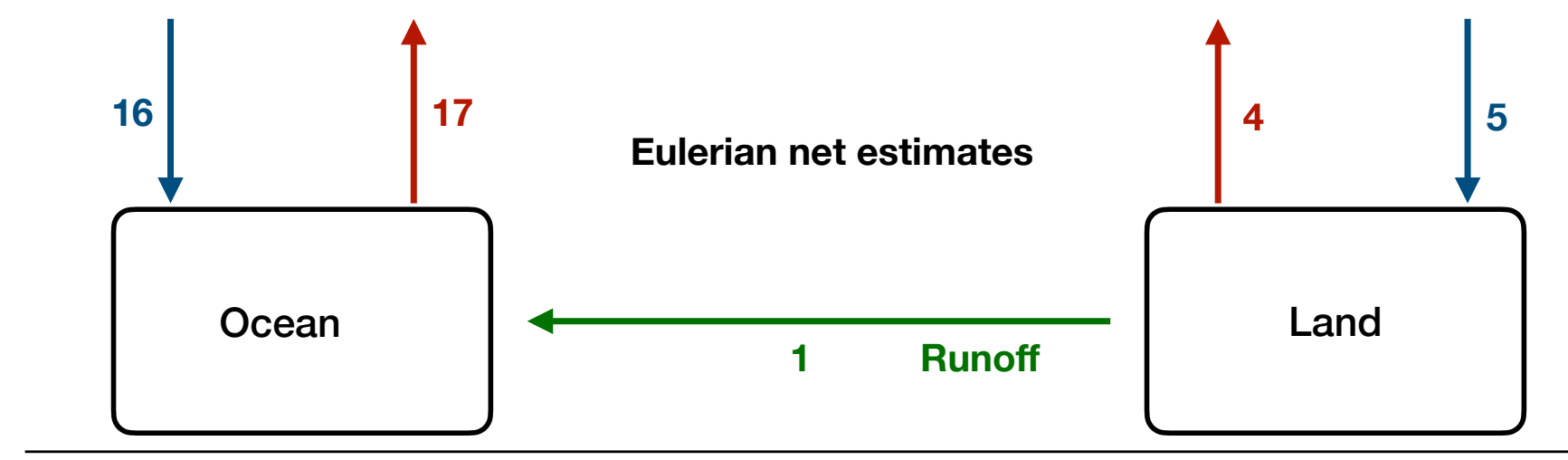

(2) $-(1)=1$

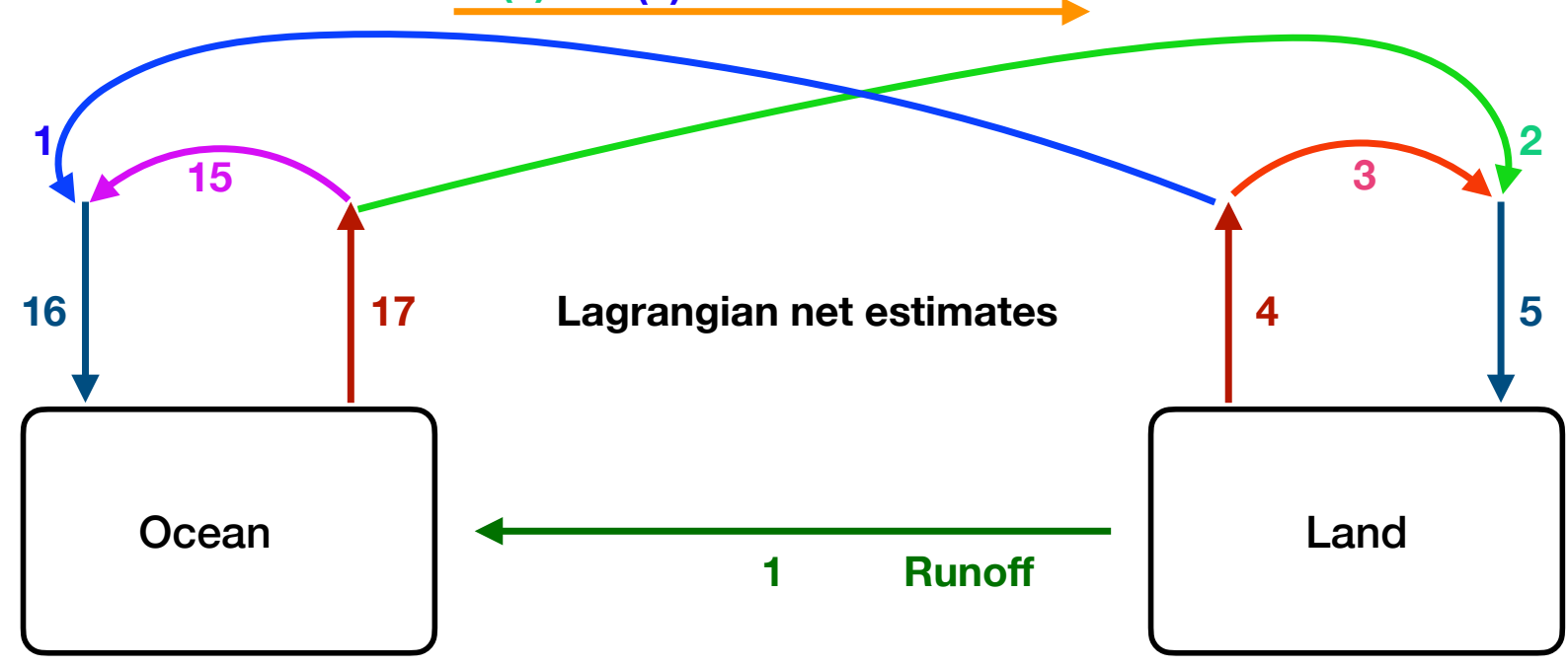

Figure 7. A sketch of the atmospheric water exchange between the Global Ocean and land. The top panel shows the Eulerian understanding of the hydrologic cycle, while the bottom panel elaborates the intricacies of the water movement that can only be obtained using a Lagrangian framework. The upward and downward arrows represent net evaporation and net precipitation transport respectively. Note, the numbers presented here are the crudely estimated transports and have not been used for any quantification.

missed a lot of detailed and important information which is essential to explain variations in continental water availability and near surface ocean salinity asymmetries. For instance, the global ocean-to-ocean, total ocean-to-land, total land-to-ocean and land-to-land water transport through the atmosphere were not quantified previously. Thus the global picture of the atmospheric water movement was incomplete. These shortcomings were overcome in the present study using a novel Lagrangian framework and presented a complete synthesised and quantitative view of the atmospheric water cycle. This Lagrangian methodology used in the present study made it possible to trace the atmospheric water transport from the evaporation to the precipitation regions 
within and between the different ocean basins and land. Earlier studies focused more on the regional or basin-scale surface water budget analysis (Alestalo, 1983; Yoon and Chen, 2005; Shi et al., 2014; Zheng et al., 2017; Liu et al., 2018), which could be viewed as a few pieces of a big puzzle. Only a handful of studies were able to put forward a quantitative and synthesized view of the global atmospheric water cycle (Chahine, 1992; Browning and Gurney, 1999; Trenberth et al., 2007, 2011). The atmospheric water transport quantification between two primary water reservoirs, e.g. ocean and land, is a straightforward issue to address. The residual between the integrated evaporation and precipitation over the ocean should be the net ocean-to land transport and must be returned to the ocean as runoff. The water-mass conservation yields that this runoff should then be equal to the difference between the integrated evapotranspiration and precipitation over land. This concept has been elaborately demonstrated in Fig. 7 (top panel) and frequently been used previously in global quantification of the atmospheric water cycle. The Eulerian method suffers, however, from limitations as it can not provide any information about how much of the ocean/land evaporated water precipitates over the ocean/land itself and is transported to the land/ocean. However, these constraints were overcome in the present study by using atmospheric water trajectories (Fig. 7, bottom panel). For example, in previous studies the net ocean-to-land water transport through the atmosphere was estimated to be around $1 \mathrm{~Sv}$ using the Eulerian method. This $1 \mathrm{~Sv}$ is practically the difference between the ocean-to-land $(\approx 2 \mathrm{~Sv})$ and land-to-ocean $(\approx 1 \mathrm{~Sv})$ transport, which is quantified in the present study and can only be obtained by applying a Lagrangian viewpoint.

The Lagrangian methodology that has been used in earlier studies was based on tracing humidity changes along air-particle trajectories and focused, in particular, on isolated aspects of the atmospheric hydrologic cycle, e.g. only ocean to river basin transport, land-to-land transport or some extreme precipitation events (Stohl and James, 2004, 2005; Van der Ent et al., 2010) and was thus unable to provide a complete picture of the global atmospheric hydrologic cycle. The tracing of humidity change along air mass trajectories might seem to be the obvious way to track water in the atmosphere, but this becomes as complex as integrating a general circulation model itself. In addition, these air-mass trajectories cannot start and end at the surface since there is no air transport through the surface. In order to trace the atmospheric water it is necessary to start and end the trajectories at the surface because atmospheric water has a transport through the surface due to evaporation and precipitation, a feature which has been possible to incorporate using the presently employed Lagrangian framework. The sorting of the atmospheric water trajectories based on their starting and ending positions made it feasible to construct a map that shows the geographic connection of the atmospheric water transport from the evaporative regions to the precipitating areas (Fig. 2). It also reveals the integrated meridional, zonal and vertical transport pathways (Fig. 3, Fig. 4 and Fig. 5 respectively) of atmospheric water that travels within and between the defined ocean basins and the landmass. Further, an average atmospheric water residence time was presented (Fig. 6) which shows how long evaporated water from a particular location remains in the atmosphere before precipitating.

In a warmer climate the atmospheric water transport is expected to be enhanced, which has far-reaching consequences. An extension of the present study could be to repeat a similar investigative strategy for future climate scenarios and identify how the atmospheric water transport within and between ocean basins and the landmass will change with respect to the present climate. The results could provide a detailed understanding of the future ocean salinity asymmetries as the ocean salinity is closely tied to the surface evaporation and precipitation, which are the starting and ending points of the atmospheric water 
https://doi.org/10.5194/hess-2021-509

Preprint. Discussion started: 1 December 2021

(c) Author(s) 2021. CC BY 4.0 License.

transport. Note that observational evidence of the oceanic salinity change already indirectly indicates a strengthening of the atmospheric branch of the water cycle (Durack and Wijffels, 2010). Additionally, future precipitation availability over the continents and the variability associated with it can also be mapped beforehand, and thus will be helpful for making strategies for the policymakers. The outcome of the present study is essential before pursuing any future climate studies regarding the global atmospheric water cycle as it provides a complete global view of water transport through the atmosphere, which was missing earlier. The present study can be used as a springboard to launch and address future water-transport issues.

Code and data availability. The Lagrangian trajectory model TRACMASS v7.0 can be freely downloaded from https://doi.org/10.5281/ zenodo.4337926. The ERA-Interim data at model levels are available from the ECMWF (https://www.ecmwf.int/en/forecasts/datasets/ archive-datasets/reanalysis-datasets/era-interim) The trajectory model TRACMASS outputs that are used to plot the figures are freely accessible at https://doi.org/10.5281/zenodo.5549573. The analysis scripts are available on request from the corresponding author.

Author contributions. D. Dey and K. Döös conceptualized the study. D. Dey collected all the necessary data sets and employed the trajectory model TRACMASS. The outputs from the TRACMASS were analyzed by D. Dey with the programming help from A. Aldama Campino. The results were then discussed elaborately between all the authors. The manuscript is written by D. Dey with inputs from all the co-authors. A. Aldama Campino was responsible for the inclusion of the cloud liquid and ice water into the updated version of the TRACMASS.

Competing interests. No potential conflict of interest was reported by the authors.

Acknowledgements. The authors wish to acknowledge Peter Lundberg and Sara Berglund for their constructive comments. This work has been financially supported by the Swedish Research Council through grant agreement no. 2019-03574. The TRACMASS model integrations and the Lagrangian trajectory computations were performed on resources provided by the Swedish National Infrastructure for Computing (SNIC) at the National Supercomputer Centre (NSC) partially funded by the Swedish Research Council through grant agreement no. 201805973. 


\section{References}

Aldama-Campino, A., Döös, K., Kjellsson, J., and Jönsson, B.: TRACMASS: Formal release of version 7.0, https://doi.org/10.5281/zenodo.4337926, 2020.

Alestalo, M.: The atmospheric water vapour budget over Europe, in: Variations in the global water budget, pp. 67-79, Springer, 1983.

Allan, R. P., Liu, C., Zahn, M., Lavers, D. A., Koukouvagias, E., and Bodas-Salcedo, A.: Physically consistent responses of the global atmospheric hydrological cycle in models and observations, Surveys in Geophysics, 35, 533-552, 2014.

Berglund, S., Döös, K., and Nycander, J.: Lagrangian tracing of the water-mass transformations in the Atlantic Ocean, Tellus A: Dynamic Meteorology and Oceanography, 69, 1306311, 2017.

Berglund, S., Döös, K., Campino, A. A., and Nycander, J.: The Water Mass Transformation in the Upper Limb of the Overturning Circulation in the Southern Hemisphere, Journal of Geophysical Research: Oceans, 126, e2021JC017 330, 2021.

Blanke, B., Arhan, M., Madec, G., and Roche, S.: Warm water paths in the equatorial Atlantic as diagnosed with a general circulation model, Journal of Physical Oceanography, 29, 2753-2768, 1999.

Broecker, W. S., Peteet, D. M., and Rind, D.: Does the ocean-atmosphere system have more than one stable mode of operation?, Nature, 315, 21-26, 1985.

Browning, K. A. and Gurney, R. J.: Global energy and water cycles, 1999.

Chahine, M. T.: The hydrological cycle and its influence on climate, Nature, 359, 373-380, 1992.

Chou, C. and Neelin, J. D.: Mechanisms of global warming impacts on regional tropical precipitation, Journal of climate, 17, 2688-2701, 2004.

Dee, D. P., Uppala, S. M., Simmons, A., Berrisford, P., Poli, P., Kobayashi, S., Andrae, U., Balmaseda, M., Balsamo, G., Bauer, d. P., et al.: The ERA-Interim reanalysis: Configuration and performance of the data assimilation system, Quarterly Journal of the royal meteorological society, 137, 553-597, 2011.

Dey, D. and Döös, K.: The coupled ocean-atmosphere hydrologic cycle, Tellus A: Dynamic Meteorology and Oceanography, 71, 1650 413, 2019.

Dey, D. and Döös, K.: Atmospheric freshwater transport from the Atlantic to the Pacific Ocean: A Lagrangian analysis, Geophysical Research Letters, 47, e2019GL086 176, 2020.

Dey, D. and Döös, K.: Tracing the origin of the South Asian summer monsoon precipitation and its variability using a novel Lagrangian framework, Journal of Climate, 34, 8655-8668, 2021.

Döös, K.: Interocean exchange of water masses, Journal of Geophysical Research: Oceans, 100, 13 499-13 514, 1995.

Döös, K., Nycander, J., and Coward, A. C.: Lagrangian decomposition of the Deacon Cell, Journal of Geophysical Research: Oceans, 113, 2008.

Döös, K., Jönsson, B., and Kjellsson, J.: Evaluation of oceanic and atmospheric trajectory schemes in the TRACMASS trajectory model v6. 0., Geoscientific Model Development, 10, 2017.

Durack, P. J. and Wijffels, S. E.: Fifty-year trends in global ocean salinities and their relationship to broad-scale warming, Journal of Climate, 23, 4342-4362, 2010.

Emile-Geay, J., Cane, M. A., Naik, N., Seager, R., Clement, A. C., and van Geen, A.: Warren revisited: Atmospheric freshwater fluxes and "Why is no deep water formed in the North Pacific", Journal of Geophysical Research: Oceans, 108, 2003.

Held, I. M. and Soden, B. J.: Robust responses of the hydrological cycle to global warming, Journal of climate, 19, 5686-5699, 2006. 
Huntington, T. G.: Evidence for intensification of the global water cycle: Review and synthesis, Journal of Hydrology, 319, 83-95, 2006.

Kjellsson, J. and Döös, K.: Lagrangian decomposition of the Hadley and Ferrel cells, Geophysical research letters, $39,2012$.

Liu, W., Sun, F., Li, Y., Zhang, G., Sang, Y.-F., Lim, W. H., Liu, J., Wang, H., and Bai, P.: Investigating water budget dynamics in 18 river

Schmitt, R. W.: Salinity and the global water cycle, Oceanography, 21, 12-19, 2008.

Shi, F., Hao, Z., and Shao, Q.: The analysis of water vapor budget and its future change in the Yellow-Huai-Hai region of China, Journal of Geophysical Research: Atmospheres, 119, 10-702, 2014.

Soden, B. J. and Held, I. M.: An assessment of climate feedbacks in coupled ocean-atmosphere models, Journal of climate, 19, 3354-3360, 2006.

Stocker, T. F., Qin, D., Plattner, G.-K., Tignor, M. M., Allen, S. K., Boschung, J., Nauels, A., Xia, Y., Bex, V., and Midgley, P. M.: Climate Change 2013: The physical science basis. contribution of working group I to the fifth assessment report of IPCC the intergovernmental panel on climate change, 2014.

Stohl, A. and James, P.: A Lagrangian analysis of the atmospheric branch of the global water cycle. Part I: Method description, validation, and demonstration for the August 2002 flooding in central Europe, Journal of Hydrometeorology, 5, 656-678, 2004.

Stohl, A. and James, P.: A Lagrangian analysis of the atmospheric branch of the global water cycle. Part II: Moisture transports between Earth's ocean basins and river catchments, Journal of Hydrometeorology, 6, 961-984, 2005.

Trenberth, K. E.: Conceptual framework for changes of extremes of the hydrological cycle with climate change, in: Weather and climate extremes, pp. 327-339, Springer, 1999.

335 Trenberth, K. E., Smith, L., Qian, T., Dai, A., and Fasullo, J.: Estimates of the global water budget and its annual cycle using observational and model data, Journal of Hydrometeorology, 8, 758-769, 2007.

Trenberth, K. E., Fasullo, J. T., and Mackaro, J.: Atmospheric moisture transports from ocean to land and global energy flows in reanalyses, Journal of climate, 24, 4907-4924, 2011.

Van der Ent, R. J., Savenije, H. H., Schaefli, B., and Steele-Dunne, S. C.: Origin and fate of atmospheric moisture over continents, Water Resources Research, 46, 2010.

Vellinga, M. and Wood, R. A.: Impacts of thermohaline circulation shutdown in the twenty-first century, Climatic Change, 91, 43-63, 2008.

Vries, P. and Döös, K.: Calculating Lagrangian trajectories using time-dependent velocity fields, Journal of Atmospheric and Oceanic Technology, 18, 1092-1101, 2001.

Wallace, J. M. and Hobbs, P. V.: Atmospheric science: an introductory survey, vol. 92, Elsevier, 2006.

Warren, B. A.: Why is no deep water formed in the North Pacific?, Journal of Marine Research, 41, 327-347, 1983.

Yoon, J.-H. and Chen, T.-C.: Water vapor budget of the Indian monsoon depression, Tellus A: Dynamic Meteorology and Oceanography, 57, 770-782, 2005.

Zheng, Z., Ma, Z., Li, M., and Xia, J.: Regional water budgets and hydroclimatic trend variations in Xinjiang from 1951 to 2000 , Climatic Change, 144, 447-460, 2017. 